\title{
Türkiye'de Öğretmen Yetiştirme Alanında Yapılan Doktora Tezlerinin İncelenmesi
}

DOI: 10.26466/opus.596629

\author{
*

\section{Hanifi Parlar* - Meral Halisdemir**} \\ * Doç. Dr, İstanbul Ticaret Üniversitesi, İnsan ve Toplum Bilileri Fakültesi, Beyoğlu / İstanbul \\ E-Posta: hanifiparlar@gmail.com \\ ORCID: 0000-0002-6313-6955 \\ ** Öğr. Gör., İstanbul Ticaret Üniversitesi, İnsan ve Toplum Bilimleri Fakültesi, Beyoğlu / İstanbul \\ E-Posta: meralhalisdemir@gmail.com \\ ORCID: $\underline{0000-0001-6023-8940}$
}

\section{Öz}

Öğretmen eğitimi çok yönlü ve geniş tabanda incelenmesi gereken konulardan biridir. Türkiye'de çok tartışılan eğitim başlıklarından olan öğretmen yetiştirmede nitelik sorunu güncelliğini korumaktadır. Öğretmen eğitiminde hızla genişleyen literatüre baktığımızda makale yazımının fazla yer tuttuğ $u$, buna karşılık tez yazımında yeterli eğilimin sergilenmediği görülmektedir. Bu çalışmanın amacı Türkiye'de öğretmen yetiştirme alanında yapılan doktora tezlerinin kapsamlı bir şekilde incelenmesi ve öğretmen yetiştirme üzerine yapılacak çalışmalara ışık tutulmasıdır. Nitel araştırma yönteminin kullanıldığı bu çalışmanın evreni, Türkiye'de eğitim bilimleri alanında yapılan doktora tezlerinden oluşmaktadır. YÖK ulusal tez merkezinden ulaşılan 25 tezin 10 tanesinin kullanımı ve yayımlanmasına izin verilmemesi nedeniyle çalışmada örneklem kapsamında ele alınan tez sayısı 15 olmuştur. Veri toplama aracı olarak araştırma kapsamında geliştirilen tematik yapı belirleme formu kullanılmış; verilerin çözümlenmesi ise içerik analizi türlerinden frekans analizi ve kategorizel analiz tekniği ile yapılmıştır. Bulgular, öğretmen yetiştirme konusunda Türkiye'de yapılan doktora çalışmalarının yeterli seviyede olmadığını göstermektedir. Bu konu üzerine daha derinlemesine ve daha çok araştırma yapılması öğretmen yetiştirme konusunda kaliteyi arttıracak, bu da doğrudan gelecek nesillerin eğitim seviyesini yükseltecektir.

Anahtar Kelimeler: Öğretmen yetiştirme, doktora tezi, kategorizel analiz 


\title{
Examination of $\mathrm{PhD}$ Thesis about Teacher Training in Turkey
}

\begin{abstract}
Teacher training is one of the issues that needs to be examined in a multidimensional and broad way. much discussed issue that the quality of teacher training in education in Turkey still keeps the current title. When we look at the rapidly expanding literature in teacher education, it is seen that article writing occupies a lot of space, whereas there is not enough tendency in thesis writing. The purpose of this study in Turkey teacher made a thorough examination of the dissertation in the field of training and teacher training to do is shed light on the works. The qualitative research method is used in this study and case study model is adopted. The universe of the study consists of the doctoral thesis in the field of science education in Turkey. The number of theses in the study was 15 in the study because 10 of the 25 theses reached from YÖK national thesis center were not allowed to be used and published. Thematic structure determination form developed within the scope of the research was used as data collection tool; and data analysis was done with frequency analysis and categorical analysis technique. The findings for teacher training shows that there is an adequate level of doctoral studies in Turkey. More in-depth and more research on this topic will improve the quality of teacher training, which will directly increase the level of education of future generations
\end{abstract}

Keywords: Teacher training, $P h D$ thesis, categoricial analysis 


\section{Giriş}

21. yüzyılda değişim rüzgarları geçen yüzyıllara göre daha hızlı esmekte ve hızla gelişen bu çağda ayakta kalmak için eğitim alanında en iyi sistemi kurmayı gerekli kılmaktadır. Bu gereklilik beraberinde ülkeler arası rekabeti de getirmiştir. Eğitim sistemiyle dünyaya örnek ve önder olan ülkelere baktı̆̆1mızda artık çok bilgi vermekten yana değil, bilgiyi birleştirip dönüştürebilmekten ve inovasyondan yana olduklarını görmekteyiz. Öğrencileri istenilen bu düzeye çıkarabilmek için öğretmen eğitimi kuşkusuz en önemli konudur.

\section{Öğretmen Yetiştirme}

Öğretmenlik mesleği "mesleklerin mesleği" olarak tanımlanmayı hak eder. Çünkü öğretmenlik, diğer mesleklerin bilişsel, devinişsel inceliklerinin öğretilmesi sürecinde rol oynayan kilit bir meslektir (Işık, Çiltaş ve Baş, 2010). Öğretmen yetiştirme; öğretmen adaylarının seçimi ve fakülte eğitimi dönemi, staj yani uygulama aşamasına geçiş dönemi ve mesleğe başladıktan sonra hizmet içi eğitim yani mesleki gelişim dönemi olmak üzere sürekli öğrenmeyi baz alan bir sistem üzerine kurgulanmıştır. Öğretmenlerin niceliksel (yeterli sayıda) ve niteliksel özellikleri bir ülkenin gelişmişlik seviyesiyle doğrudan ilişkilidir.

İyi ve nitelikli bir eğitimi, nitelikli öğretmenler yapar. Bundan dolayı, "bir okul, ancak, içindeki öğretmenler kadar iyidir" denilebilir (Kavcar, 2002). "Kaliteli eğitimin başarının anahtarı olduğu" konusundaki artan farkındalık yeniliklere ve dolayısıyla da ilerlemelere yol açmıştır. Özellikle son yıllarda öğretmen profilini ortaya çıarmak için dikkat çekici çabalar sarf edilmektedir (Canado, 2018). Nitelikli öğretmenlerin yetiştirilmesi için eğitim sistemin sürekli ve her yönden değerlendirilmesi gereklidir. Üniversitelerin nitelikli öğretmen yetiştirmeyi hedefleyen çalışmaları, değişen zamana ve ihtiyaca göre yeniden şekillenmeli, güncel ve bilimsel olmalı, yeni kuşağın ihtiyacına yönelik pratik tekniklerle ve teknolojik altyapıyla donatılmalıdır.

Amerika Birleşik Devletleri'nde, son dönem başkanlık yönetimlerinin ana hedeflerinden biri, her sınıfta "yüksek nitelikli bir öğretmen" olmasıdır. Son araştırmalar, öğretmen kalitesinin öğrencinin başarısını arttırmasındaki merkezi rolünü de belgelemiştir (Harris ve Sass, 2011). Eğitimdeki modern yaklaşımlar, öğretmenlerin, eğitim sürecinin diğer üyeleriyle iş birliğini organize 
edebilmelerini, müfredat ve ders dışı etkinlikler sırasında orijinal ve fonksiyonel ürünler hazırlama sürecine öğrencilerin yaratıcılığını dahil etmelerini, her öğrencinin ahenkli kişilik gelişimi üzerine odaklanmalarını teşvik eder. Yenilikçi öğrenme teknolojilerini kullanan öğretmenler, genç kuşakların eğitiminin garantörleridir. Gelecekteki uzmanların nitelikleri, aldıkları eğitiminin etkinliğine, öğretmenlerinin pedagojik aktivite becerilerine, teknolojik altyapılarına ve mesleki yeterliliklerine bağlıdır. Bu nedenle, ulusal eğitim sisteminin iyileştirilmesinin ana yönlerini analiz etmek ve belirlemek için özellikle de eğitmedeki yabancı deneyimleri incelemek gerekir (Androshchuk ve Androshchuk, 2017).

Ülkemiz son 150 yıldır değişik (bazen çelişik) öğretmen eğitim sistemlerinin geliştirildiği, uygulamaya konulduğu ülkelerden birisi olmuştur (Üstüner, 2004). Türkiye'de, eğitim fakültelerine öğrenci seçme sürecinin, öğretmen yetiştirme sisteminin teknik ve akademik boyutlarının yeniden irdelenerek gözden geçirilmesi; öğretmenlik programları derslerinin, genel kültür, öğretmenlik meslek bilgisi ve okul uygulamaları boyutlarına daha fazla ağırlık verilmesi ve süreç sonunda canlı olarak performans sergileyebilecekleri uygulama sınavlarından geçirilmeleri gerektiği sonuçlarına ulaşılmıştır. Mesleğe atanmadan önceki süreçte ise, öğretmen adaylarının, her branş için alan bilgilerini de ölçmeye yönelik mesleki sınavların yapılması gerektiği düşünülmektedir (Atanur, Baskan ve Aydın, 2006).

Eğitim araştırmaları, dünya çapında eğitim uygulamalarını etkilemek ve bilgilendirmek açısından önemli bir rol oynamaktadır. Yayınlanan eserlerden bazıları, birçok yerde eğitim reformunun temelini oluşturmaktadır. Nitekim, son on yılda eğitim araştırma dergilerinde yayınlanan makalelerin sayısının arttı̆̆ görülmektedir (Onwuegbuzie ve Daniel, 2003). Araştırmaların senteziyle ilgili kalite güvencesi için uygulanabilir olan tek sistematik yaklaşım; eğitim araştırmacılarını eğitmek ve kendilerine karşı sağlıklı bir özeleştiri geliştirmelerini teşvik etmektir (Dunkin, 2013). Bir alanda yapılmış bilimsel tezlerin analiz edilmesi, o konunun derinliği ve yaygınlığı hakkında bilgiler verebilir, incelenen alanın genel görünümünü ortaya çkarabilir (Karadağ, 2009).

Bu çalışmanın amacı "Türkiye'de öğretmen yetiştirme alanında yapılan doktora tezleri" ni içerik açısından inceleyip, mevcut durumu ortaya koymak ve gelecekte yapılması muhtemel çalışmalara yol göstermektir. Araştırmanın 
belirtilen amacı doğrultusunda aşağıda bulunan araştırma sorularına cevaplar aranmıştır.

1. Ulaşılan tezlerin yıllara göre dağılımı nasıldır?

2. Ulaşılan tezlerin illere göre dağılımı nasıldır?

3. Ulaşılan tezlerin üniversitelere göre dağılımı nasıldır?

4. Ulaşılan tezlerin enstitülere göre dağılımı nasıldır?

5. Ulaşılan tezlerin anabilim dallarına göre dağılımı nasıldır?

6. Ulaşılan tezlerin konusu nedir?

7. Ulaşılan tezlerin araştırma yöntemine göre dağılımı nasıldır?

8. Ulaşılan tezlerin araştırma tekniğine göre dağılımı nasıldır?

9. Ulaşılan tezlerin veri toplama aracı nedir?

10. Ulaşılan tezlerin tez örneklemi/çalışma grubu nedir?

11. Ulaşılan tezlerin kullanılan istatistiki analizleri nelerdir?

12. Ulaşılan tezlerin yazım dili nedir?

13. Ulaşılan tezlerin kullanılan kaynak türleri nelerdir?

14. Tez danışmanlarının adları ve unvanları nelerdir?

\section{Yöntem}

\section{Çalışmanın Deseni}

Türkiye'de öğretmen yetiştirme alanında yapılan doktora tezlerinin incelenmesinin amaçlandığı bu çalışma nitel araştırma yöntemine göre planlanmış, tarama modelinde betimsel bir araştırmadır. Nitel veri analizi, insanı merkeze alan, onun kendisi ve çevresini nasıl algıladığı ve tanımladığını keşfetmeye yönelik çabalardan biridir. Nitel analiz süreci verilerin kapsamlı bir betimlemesi ile başlamaktadır. Ardından, veri seti içerisinde örtük olarak duran temalar, sınıflandırma yoluyla ortaya çıkartılmakta ve bu temalar birbirleri ile ilişkilendirilerek inceleme konusu olan sosyal gerçeklik açıklanmaya çalışılmaktadır (Özdemir, 2011).

\section{Evren ve Örneklem}

Türkiye'de öğretmen yetiştirme alanında yapılan doktora tezlerine ulaşmak için çalışmanın kuramsal evreni YÖK Yayın Dokümantasyon Daire Başkanlığ tarafından 1986 yılından itibaren arşivlenen eğitim bilimleri alanındaki 
doktora tezlerine ulaşılmıştır. YÖK ulusal tez merkezinden 1987-2019 yılları arasında yazılmış 25 tez elde edilmiştir. Bunların 10'unun kullanımı ve yayımlanmasına izin verilmemesi nedeniyle çalışmada örneklem kapsamında ele alınan tez sayısı 15'tir (YÖK, 2018).

\section{Veri Toplama Araci}

Bu çalışma kapsamında veri toplamak amacıyla öğretmen yetiştirme ve geliştirmeye ilişkin yapılan çalışmaları inceleme formu hazırlanmıştır. Uzman görüşleri alınarak son şekli verilen formda yer alan kriterler ise şunlardır; yıl, il, üniversite, enstitü, anabilim dalı, tez konusu, konu içerikleri, araştırma yöntemi, araştırma tekniği, veri toplama aracı, tez örneklemi/çalışma grubu, kullanılan istatistiki analizler, yazım dili, kullanılan kaynak türleri, tez yazar cinsiyeti, danışman cinsiyeti, danışman adı ve unvanıdır.

\section{Verilerin Toplanması}

Araştırmaya dâhil edilecek çalışmaların belirlenmesinde YÖK Ulusal Tez Merkezi veri tabanı kullanılmıştır. Ulaşılan 25 tezden 10'unun kullanımı ve yayımlanmasına izin verilmemesi nedeniyle çalışmada örneklem kapsaminda incelenen tez sayısı 15 olmuştur.

\section{Verilerin Analizi}

Araştırmada elde edilen veriler Excel programına aktarılmış ve özet tablolar kullanılarak analizler yapılmıştır. Yapılan kategorik çözümleme tez yazarlarının çalışmalarında belirttikleri esaslar doğrultusunda yürütülmüştür. Çalışmada elde edilen veriler, içerik analiz türlerinde kategorizel analiz ve frekans analizi teknikleri kullanılarak çözümlenmiștir. Kategorizel analiz sürecinde; verilerin kodlanması, temaların olușturulması ve düzenlenmesi ile bulguların tanımlanması ve yorumlanması aşamaları izlenmiştir.

\section{Bulgular}

Çalışmada belirlenen alt amaçlarda belirtildiği üzere; ulaşılan tezlerin yıllara göre dağılımı, illere göre dağılımı, üniversitelere göre dağılımı, enstitülere 
göre dağılımı, anabilim dallarına göre dağılımı, konusu, araştırma yöntemine göre dağılımı, araştırma tekniğine göre dağılımı, veri toplama aracı, tez örneklemi/çalışma grubu, kullanılan istatistiki analizleri, yazım dili, kullanılan kaynaklar ve tez danışmanlarının adları ve unvanlarına ilişkin elde edilen bulgular aşağıda grafikler ve tablolar halinde sunulmuştur.

\section{Öğretmen Yetiştirme Konusunda Yapılan Araştırmalarnn Yıllara Göre Dağılımı}

Tablo 1 incelendiğinde, öğretmen yetiştirme konusunda yapılan çalışmaların yıllara göre seyrek dağıldığı görülmektedir. Bununla birlikte böyle önemli bir konuda yazılmış tez sayısının 15 olması konu üzerine yapılan çalışmaların yetersiz olduğunu ortaya koymaktadır.

Tablo 1. Çalışmaların yıllara göre dağılımı

\begin{tabular}{ll}
\hline Çalışmaların ylllara göre dağlımı & Sıklk \\
\hline 1987 & 1 \\
\hline 1988 & 1 \\
\hline 1995 & 1 \\
\hline 1996 & 2 \\
\hline 1999 & 1 \\
\hline 2000 & 1 \\
2001 & 1 \\
\hline 2006 & 2 \\
\hline 2013 & 2 \\
\hline 2016 & 2 \\
\hline 2017 & 1 \\
\hline Toplam & 15 \\
\hline
\end{tabular}

\section{Öğretmen Yetiştirme Konusunda Yapılan Araştırmaların İllere Göre Dağılımı}

Tablo 2 incelendiğinde, öğretmen yetiştirme konusu üzerine en yoğun çalışan akademisyenlerin Ankara ilinden olduğu görülmektedir. Ankara'yı s1rasıyla İzmir ve Konya şehirleri izlemektedir. En çok üniversitenin yer aldığı İstanbul'dan sadece bir çalışma çıkması dikkat çekmektedir. 
Tablo 2. Çalışmaların illere göre dă̆ılımı

\begin{tabular}{ll}
\hline Çalışmaların illere göre dağılımı & S1klık \\
\hline Ankara & 5 \\
\hline Çanakkale & 1 \\
\hline Elazı̆ & 1 \\
\hline Eskişehir & 1 \\
\hline İstanbul & 1 \\
\hline İmir & 3 \\
\hline Konya & 2 \\
\hline Mersin & 1 \\
\hline Toplam & 15 \\
\hline
\end{tabular}

Öğretmen Yetiştirme Konusunda Yapılan Çalışmaların Üniversitelere Göre Dă̆ılımı

Tablo 3 incelendiğinde, öğretmen yetiştirme konusunda doktora tezi en çok olan üniversitelerin Ankara ve Dokuz Eylül Üniversiteleri olduğu görülmektedir. Diğer illerde ise dengeli bir dağılım sergilenmiştir.

Tablo 3. Çalışmaların üniversitelere göre dă̆ılımı

\begin{tabular}{ll}
\hline Çalışmaların üniversitelere göre dağılımı & Sıklık \\
\hline Ankara Üniversitesi & 3 \\
\hline Dokuz Eylül Üniversitesi & 3 \\
\hline İstanbul Üniversitesi & 1 \\
\hline Orta Doğu Teknik Üniversitesi & 1 \\
\hline Çanakkale Onsekiz Mart Üniversitesi & 1 \\
\hline Hacettepe Üniversitesi & 1 \\
\hline Eskişehir Osmangazi Üniversitesi & 1 \\
\hline Mersin Üniversitesi & 1 \\
\hline Frat Üniversitesi & 1 \\
\hline Selçuk Üniversitesi & 1 \\
\hline Necmettin Erbakan Üniversitesi & 1 \\
\hline Toplam & 15 \\
\hline
\end{tabular}

\section{Öğretmen Yetiştirme Konusunda Yapılan Çalışmalarn Enstitülere Göre Dağılımı}

Tablo 4 incelendiğinde, öğretmen yetiştirme konusunda en çok çalışan enstitülerin sosyal bilimler enstitüsü olduğu görülmektedir. Bu konuda öne çıkması beklenen eğitim bilimleri enstitülerinin geride kalması dikkat çekmektedir. 
Tablo 4. Çalışmaların enstitülere göre dă̆ılımı

\begin{tabular}{cll}
\hline & Çalı̧̧maların enstitülere göre dağılımı & Sıklık \\
\hline 1. & Sosyal Bilimler Enstitüsü & 9 \\
\hline 2. & Eğitim Bilimleri Enstitüsü & 5 \\
\hline 3. & Atatürk İlkeleri ve İnkılap Tarihi Enstitüsü & 1 \\
\hline 4. & Toplam & 15 \\
\hline
\end{tabular}

\section{Öğretmen Yetiştirme Konusunda Yapılan Çalışmaların Anabilim Dalla- rına Göre Dă̆ılımı}

Tablo 5 incelendiğinde, öğretmen yetiştirme konusunda en çok çalışma ortaya koyan anabilim dalı eğitim bilimleri anabilim dalıdır.

Tablo 5. Çalışmaların anabilim dallarına göre dă̆ılımı

\begin{tabular}{llc}
\hline & Çalışmaların anabilim dallarına göre dağılımı & Sıklık \\
\hline 1. & Eğitim Bilimleri Anabilim Dalı & 6 \\
\hline 2. & Eğitim Programları ve Öğretim Anabilim Dalı & 3 \\
\hline 3. & Felsefe ve Din Bilimleri Ana Bilim Dalı & 2 \\
\hline 4. & Eğitim Yönetimi, Teftişi, Planlaması ve Ekonomisi Anabilim Dalı & 1 \\
\hline 5. & Yabancı Diller Eğitimi Anabilim Dalı & 1 \\
\hline 6. & Anabilimdalı belli olmayan & 2 \\
\hline & Toplam & 15 \\
\hline
\end{tabular}

Öğretmen Yetiştirme Konusunda Yapılan Çalışmaların Tez Konularına Göre Dağılımı

Tablo 6'da öğretmen yetiştirme ile ilgili yazılan tezlerin konuları görülmektedir. Konu açısından çeşitlilik görülmekte ancak ihtiyaç duyulan, güncel konuların eksikliği dikkat çekmektedir. Öğretmen yetiştirmeyle ilgili konu yelpazesinin oldukça geniş olduğu düşünüldüğünde, akademisyenlerimizin bu alana daha çok yönelmesi gerekmektedir. 
Tablo 6. Çalışmaların konularına göre dağılımı

Tez Tez konusu

Okul Teknoloji Planlaması: İlköğretim Okulları İçin Uygulamalı Bir Model Önerisi ve Öğretmen Yetiştirme Sistemi Açısından Sonuçları

Din Kültürü ve Ahlak Bilgisi Öğretmen Yetiştirme Programlarına İlişkin Kalite Standartlarının Belirlenmesi

Türkiye'de Yüksek Din Öğretimi Kurumları Programlarının Öğretmen Yetiştirme Bakımından Değerlendirilmesi

Öğretmen Yetiştirmede Mikro Öğretim Yönteminin Etkililiği (F.Ü. Teknik Eğitim Fakültesi Örneği)

Öğretmen Adaylarının Cumhuriyet' in Kuruluşundan Günümüze Öğretmenlik Mesleğinin Tarihsel Gelişimi Konusundaki Bilgi Düzeyleri ve Bir Ders Programı Önerisi (Türkiye'de Öğretmen Yetiştirme) Öğretmen Yetiştirme Standartları Konusunda Bir Sistematik Literatür İnceleme

Türkiye'de Öğretmen Yetiştirme Uygulamalarında Yabancı Uzmanların Yeri

Öğretmen Yetiştirmede 3580 Sayılı Yasayla Getirilen Parasız Yatılılık ve Bursluluk Uygulaması

Türkiye'de Ortaöğretime Öğretmen Yetiştirme Sisteminin Pedagojik Temelleri

Yabancı Dil Öğretmen Yetiştirme Programlarında Öğretmen Bilişselliği: Öğretmen Adaylarının Sınıf İçi Eğitsel Kararlarının Kaynakları

Developing Reflectıve Teachers: A Study on Perception and Improvement of Reflection In Pre-Service Teacher Education

Öğretmen Yetiştirmede Öğrencilerin Akademik, Mesleki ve Kişisel Gelişimlerine İlişkin Yönetsel Uygulamalar

Türkiye'de Ortaöğretime Öğretmen Yetiştirme Problemi

Öğretmen Yetiştirme Programlarına İlişkin Kalite Standartlarının Belirlenmesi ve Fakültelerin Standartlara Uygunluğunun Değerlendirilmesi

Öğretmen Yetiştirmede Ankara Yüksek Öğretmen Okulu Uygulaması

\section{Öğretmen Yetiştirme Konusunda Yapılan Çalışmalarn Araştırma Yöntem- lerine Göre Dă̆̊lımı}

Tablo 7'ye göre en çok tercih edilen araştırma yönteminin nicel yöntem olduğu görülmektedir. Araştırma sonuçları, çalışmaların nitel ve karma yöntemle daha fazla yapılmasına ihtiyaç olduğunu göstermektedir. Böylece konunun, içeriğinin zenginleştirilmesi ve derinlemesine incelenmesi sağlanmış olacaktır.

Tablo 7. Çalışmaların araştırma yöntemlerine göre dağılımı

\begin{tabular}{clc}
\hline \multicolumn{2}{c}{ Çalışmaların araştırma yöntemlerine göre dağılımı } & Sıklık \\
\hline 1. & Nicel & 8 \\
\hline 2. & Nitel & 4 \\
\hline 3. & Karma & 3 \\
\hline & Toplam & 15 \\
\hline
\end{tabular}




\section{Öğretmen Yetiştirme Konusunda Yapılan Çalışmaların Araştırma Tekniğine Göre Dağılımı}

Tablo 8'e göre çalışmalarda kullanılan araştırma tekniği çeşitlilik göstermektedir. Tarama modeli ve sistematik literatür inceleme yöntemlerinin en çok tercih edilen yöntemler olduğu dikkat çekmektedir.

Tablo 8. Çalışmaların araştırma tekniklerine göre dağılımı

\begin{tabular}{|c|c|}
\hline Araştırma tekniği & Sıklık derecesi (f) \\
\hline 1. Anket ve içerik analizi & 1 \\
\hline 2. Tarama modeli & 3 \\
\hline 3. İlişkisel tarama & 1 \\
\hline 4. Deneysel model & 1 \\
\hline 5. Siralı karma desen & 1 \\
\hline 6. Sistematik literatür inceleme yöntemiyle (Kuramsal analiz ve tarama-anket tekniği) & 3 \\
\hline 7. Betimsel analiz & 1 \\
\hline 8. Olgubilim, görüşme, gözlem & 2 \\
\hline 9. Durum çalışması tekniği & 1 \\
\hline 10. Tarama ve görüşme tekniği & 1 \\
\hline Toplam & 15 \\
\hline
\end{tabular}

\section{Öğretmen Yetiştirme Konusunda Yapılan Çalışmaların Veri Toplama Araçlarnna Göre Dă̆ılımı}

Tablo 9 öğretmen yetiştirme konusunda yapılan çalışmaların veri toplama araçlarına göre dağılımını göstermektedir. Buna göre en çok tercih edilen veri toplama aracının anket olduğu görülmektedir.

Tablo 9. Çalışmaların veri toplama araçlarına göre dă̆ılımı

\begin{tabular}{lll}
\hline Veri toplama aracı & \multicolumn{2}{c}{ Sıklık derecesi (f) } \\
\hline $\begin{array}{l}\text { 1. } \\
\text { Din kültürü ve ahlak bilgisi öğretmen yetiştirme programlarında kalite standart- }\end{array}$ & 1 \\
\hline ları DKÖPKS ölçeği. & Anket & 5 \\
\hline 3. & İki tür ölçek ve bir anket olmak üzere 3 tür veri toplama aracı & 1 \\
\hline
\end{tabular}


4. Yarı yapılandırılmış açık uçlu sorulardan oluşan görüşme formu ve bilgi testi

5. Öğretmen yetiştirme sistemine bağlı insan kaynaklarına ilişkin istatistiksel veriler, ÖSYM ve YBSB veri tabanları

6. MEB arşivi

7. Anket ve görüşme formu

8. Yönlendirme eşliğinde tutulan haftalık günlükler, banda kaydedilmiş yansıtıcı etkileşimler ve görüşmeler, öğrencilerin kısa derslerinin video kayıtlarının analizi, anketler ve gözlemler

9. Yarı yapılandırılmış görüşme formu

\title{
Öğretmen Yetiştirme Konusunda Yapılan Çalışmalarn Tez Örnekle- mine/Çalışma Gruplarna Göre Dă̆ılımı
}

\author{
Tablo 10'da çalışmaların tez örneklemine /çalışma gruplarına göre dağılımı \\ gösterilmiştir
}

Tablo 10. Çalışmaların tez örneklemine /çalışma gruplarına göre dağılımı

Tez Tez örneklemi / çalışma grubu

1.Özel bir ilkokul

2.Çalışma grubu üç farklı gruptan oluşmaktadır: öğretim elemanları, öğretmen adayları ve öğretmenler

3.Öğretim elemanları, lisans son sinıf öğrencileri ve öğretmenler

4.Öğretmen adayı 3.ve 4. sinıf lisans öğrencileri

5.Alan uzmanları ile öğretmen adayları

6.YÖK ve ÖSYM verileri

7.MEB talim terbiye kurum kararlarının 1923-1960 yılları arası tutanakları, doküman incelemesi

8. 3 farklı evren vardır:

1. Evren 1988-1990 ÖSYS sonuçlarına göre eğitim fakülteleri ile fen-edebiyat fakülteleri taban ve tavan puanları,

2. Evren: 1988-1990 yılları ÖSYS öğretmen ve eğitim uzmanı yetiştiren yükseköğretim programlarını ilk on sırada tercih edenler,

3. Evren: öğretmen yetiştiren programlara 1990 yılında kaydolan ve 3580 sayılı yasadan yararlanan öğrenciler.

9.Yurdun batı, orta ve doğu bölgelerinden seçilen okulların öğrencileri.

10. Öğretmen adayları

11.Son sınıftan seçilen öğretmen adayları.

12.Dekan ve bölüm başkanları

13.Öğretmenler

14.Öğretim üyesi, öğretim görevlisi, öğretim yardımcısı, öğretmenler ve öğretmen adayları

15.Öğretmenler 


\section{Öğretmen Yetiştirme Konusunda Yapılan Çalışmaların Kullanılan İstatis- tiki Analizlere Göre Dağılımı.}

Tablo 11'de öğretmen yetiştirme konusunda yapılan çalışmalarda kullanılan istatistiki analizlere göre dağılımı gösterilmiştir. En çok betimleyici istatistiki analizlerden; frekans, yüzde ve aritmetik ortalama analizinin kullanıldığı görülmektedir.

Tablo 11. Çalışmalarda kullanılan istatistiki analizlere göre dağılım.

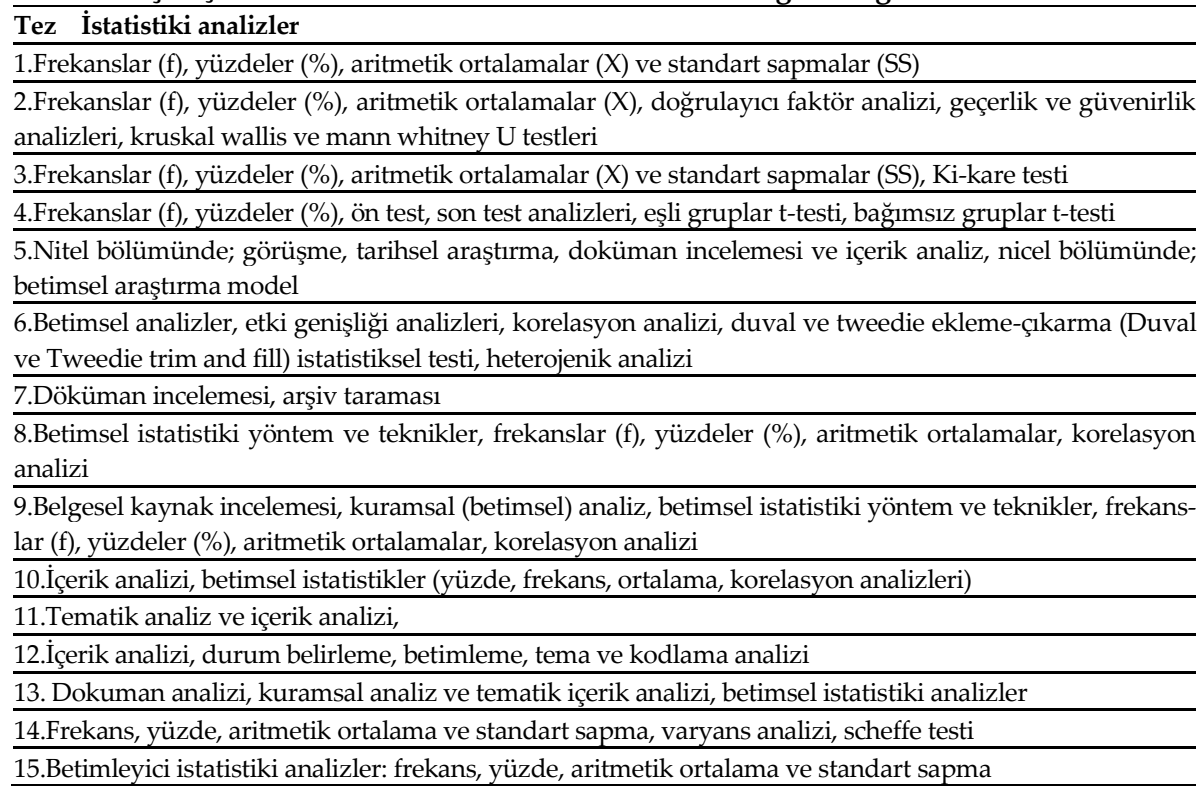

\section{Öğretmen Yetiştirme Konusunda Yapılan Çalışmaların Yazım Dillerine Göre Dağılımı}

Tablo 12. Çalışmaların araştırma yazım dillerine göre dă̆ılımı Çalışmaların yazım dillerine göre dağılımı

\begin{tabular}{lll}
\hline 1. & Türkçe & 13 \\
\hline 2. & İngilizce & 2 \\
\hline & Toplam & 15 \\
\hline
\end{tabular}


Tablo 12'ye göre tez yazımının en çok ana dilde tercih edildiği görülmektedir. Uluslararası kabul gören akademik çalışma dili olan İngilizce sınırlı sayıda kalmıştır. Bu da çalışmaların uluslararası platformda oldukça düşük bir seviyede kaldığını göstermektedir.

\section{Öğretmen Yetiştirme Konusunda Yapılan Çalışmaların Kullanılan Kaynak Türlerine Göre Dağılımı}

Tablo 13'te öğretmen yetiştirme konusunda yapılan çalışmaların kullanılan kaynak türlerine göre dağılımı gösterilmiştir.

Tablo 13. Çalışmaların kullanılan kaynak türlerine göre dağılımı

Tez Kullanılan kaynak türleri

1.Kitap ve dergiler, makaleler, tezler, internet kaynakları.

2.Kitap ve dergiler, makaleler, tezler, internet kaynakları.

3.Medrese ve ilahiyat fakültesi tarihçeleri içeren eserler, sempozyum kongre şura ve toplantılarda sunulan tebliğler, tezler ve makaleler.

4.Kitap ve dergiler, makale ve tezler, sempozyum ve şura bildirileri.

5.Kitaplar, tezler ve makaleler.

6.Kitap ve dergiler, makaleler, tezler, internet kaynakları.

7.Arşiv belgeleri, uzman raporları, süreli yayınlar, kitap ve makaleler, tezler.

8.Kitap ve dergiler, makaleler, tezler, kalkınma planları, raporlar, resmi gazete.

9.Kitap ve dergiler, araştırmalar, yasa ve yönetmelikler.

10.Kitap ve dergiler, makaleler, tezler.

11.Kitap ve dergiler, makaleler, tezler.

12.Kitap ve dergiler, makaleler, tezler, internet kaynakları, raporlar.

13.Kitap ve dergiler, makaleler, tezler, sempozyum raporları, yönetmelikler, kararnameler, resmi gazete, tebliğler dergisi, enstitü programları, şuralar, kanunlar, raporlar, MEB ile ilgili söylev ve demeçler.

14.Kitap ve dergiler, makaleler, tezler, internet kaynakları ve raporlar.

15.Kitap ve dergiler, gazeteler, raporlar, okul arşivleri.

Öğretmen Yetiştirme Konusunda Çalışan Tez Danışmanlarının Adlan ve Unvanlarına Göre Dă̆ılımı

Tablo 14'te öğretmen yetiştirme konusunda çalışan tez danışmanlarının adları ve unvanlarına göre dağılımı yer almaktadır. 
Tablo 14. Tez danışmanlarının adları ve unvanlarnna göre dağılımı

\begin{tabular}{cll}
\hline Tez & Unvan & \multicolumn{1}{c}{ Ad- Soyad } \\
\hline 1. & Prof. Dr. & Halil İbrahim YALIN \\
\hline 2. & Prof. Dr. & Mustafa TAVUKÇUOĞLU \\
\hline 3. & Prof. Dr. & Selahattin PARLADIR \\
\hline 4. & Prof. Dr. & Şadiye G. KÜLAHÇI \\
\hline 5. & Prof. Dr. & Özler ÇAKIR (Eş Danısman Doç. Dr. Devrim ALICI) \\
\hline 6. & Prof. Dr. & Ayhan AYDIN \\
\hline 7. & Prof. Dr. & Salih ÖZBARAN \\
\hline 8. & Prof. Dr. & Sudi B̈̈LBÜL \\
\hline 9. & Prof. Dr. & İlter AKAT \\
\hline 10 & Prof. Dr. & Necmettin Kamil SEVIL \\
\hline 10. & Prof. Dr. & Ali YILDIRIM \\
\hline 11. & Prof. Dr. & Cengiz AKÇAY \\
\hline 12. & Prof. Dr. & Hasan Ali KOÇER \\
\hline 13. & Prof. Dr. & Mehmet A. KISAKÜREK \\
\hline 14. & Prof. Dr. & Yahya AKYÜZ
\end{tabular}

\section{Sonuç ve Öneriler}

Bu çalışmada Türkiye'de öğretmen yetiştirme alanında yapılan doktora tezleri; yıl, il, üniversite, enstitü, anabilim dalı, tez konusu, konu içerikleri, araştırma yöntemi, araştırma tekniği, veri toplama aracı, tez örneklemi/ç̧alışma grubu, kullanılan istatistiki analizler, yazım dili, kullanılan kaynak türleri, tez yazar cinsiyeti, danışman cinsiyeti, danışman adı ve unvanları açısından incelenmiştir.

Eğitim reformu hareketleri öğretmen eğitimiyle doğrudan bağlantılıdır (Ültanır ve Ültanır, 2018). Yapılan çalışmada doktora seviyesinde öğretmen yetiştirme konusunda yeterli tez çalışması yapılmadığ ortaya çıkmıştır. Bu da ülkemizde yapılan eğitim reformları, sistem değişiklikleri düşünüldügünde, öğretmen yetiştirmeye yönelik çalışmaların aynı doğrultuda ilerlemediğini göstermektedir. Sitemde birbirini yakalayamayan, bir bütünlük ve paralellik sergilemeyen olgusal bir boşluk görülmektedir. Alabaş ve Y1lmaz (2018)'ın çalışmasında geçen; aday öğretmenleri ve eğitimlerini değerlendiren katılımcı mentor öğretmenlerin "programın daha üretken olması gerektiğini" dile getirmeleri, bu çalışmamızdan çıkan "öğretmen yetiştirmeye yönelik araştırmaların yetersiz olduğu" sonucuyla örtüşmektedir. Şöyle ki; doktora seviyesinden öğretmen yetiştirmeye yönelik nokta atışı tespitlerin yapılması ve tespit edilen zayıf yönlerin iyileştirilmesine yönelik 
önerilerin verilmesi, eğitim fakültelerinin programlarını gözden geçirmelerini sağlayacak, sınıfın dört duvarı içinde verilen teorik derslerle gerçek pedagojik uygulamalar arasındaki uçurumu kapatmaya yardım edecektir. Böylece yukarıdaki çalışmada da geçen aday öğretmenlerin daha etkin ve verimli bir süreçten geçmesini, mentor öğretmenlerinden de daha iyi bir geçer not almalarını ve yetkin birer öğretmen olmalarını sağlayacaktır.

Balbay ve arkadaşlarının (2018) yaptı̆̆ çalışmaya göre; Türkiye'deki kurumların çoğunda, eğitim programları ile öğretmenlerin bağlamsal ihtiyaçları arasında bir boşluk bulunmaktadır. Sistematik programlar yapılmamaktadır ve genellikle kısa süreli eğitim programları sunan sınırlı sayıda profesyonel ve yayıncı vardır. Yeterli sayıda profesyonel personel bulunmadığı ve öğretmenlerin birlikte nasıl çalışacaklarını bilmedikleri ortaya çıkmıştır. Ayrıca, eğitimlerdeki geri bildirim sistemi de etkisizdir. Bu noktada geribildirimler kadar durum analizi yapmak ve iyileştirme önerileri sunmak büyük önem taşımaktadır. Öğretmen yetiştirme alanında doktora çalışmalarına duyulan ihtiyaç açıça görülmektedir.

Çalışmaların yazım dilinin genelde Türkçe olması uluslararası alanda okunurluk oranını düşürmektedir. İngilizce tez yazımı ve yayımlanması akademik doyumluluk açısından önemlidir. Lisansüstü araștırmaların ve tezlerin yabancı dilde yazılması için teşvik gerektiği gözlemlenmiştir.

Niteliksel araştırmaların yürütülmesine olan ilgi son yıllarda uluslararası kalkınma alanındaki araştırma projelerinin sayısının artması nedeniyle yükselişe geçmiştir. Bu gelişme organizasyonları ve akademisyenler tarafından karmaşık durumları daha iyi anlamak, gelecekteki uygulamaları ve politikaları bilgilendirmek ve değerlendirmek için yürütülen çeşitli çalışmalarda görülebilir (Schulz, 2014). Yapılan bu çalışmada araştırma yöntemlerinden nicel yöntemin yoğun bir şekilde tercih edildiği, nitel ve karma modellerin ise dengeli fakat az uygulandığı görülmüştür. Daha derinlemesine bilgi toplama imkânı sunması sebebiyle araştırmacılar nitel ve karma yöntemlerle de çalı̧̧maya teşvik edilmelidir. Özellikle daha iyi bir eğitim vizyonu benimsemek, temel kavramlara odaklanmak, pratik bağlantıları geliştirmek ve topluca belirli iyileştirmelere işaret eden çalışmaları sentezleyebilmek için nitel araştırma gerekmektedir (Gaff, 1982). Araştırmalara göre uluslararası alanda nitel veri yorumlama tekniklerinin geliştiği bilinmekte ve elde edilen sonuçlar nicel veri ile elde edilen sonuçlar kadar ge- 
çerli sayılmaktadır. Artık nitel ve karma model yolu ile de fazla veri ve sonuca ulaşılabilir. Böylece öğretmen yetiştirme alanındaki grift temalar daha derinlemesine ve her yönüyle incelenmiş olacaktır.

Durdukoca (2018)'nın yaptığı araştırma sonucuna göre; katılımcı öğretmenlerin, Türkiye'deki öğretmen yetiştirme sistemi hakkında genel olarak olumsuz görüsslere sahip oldukları görülmüştür. Katılımcılara göre, öğretmen eğitim kurumları ile öğretmen istihdam eden kurumlar arasında zayıf bir koordinasyon vardır. Ayrıca formasyon eğitimi sertifika programı ile öğretmen eğitim sisteminin sonlandırılması gerektiği vurgulanmıştır.

Son yıllarda alanyazında kaynaklarının artmasına rağmen, 1987'den itibaren yazılmış doktora tezlerinin bu kadar az sayıda olması Türkiye'de bu konuya nerdeyse hiç önem verilmediğini göstermektedir. Bu durumun iyileştirilmesi için doktora tezi yazacak kişilerin daha fazla bu alana yönelmesi/yönlendirilmesi, doktora tezlerine seçilecek temalar konusunda dikkatli olunması, gözlenen sorunların her yönüyle ele alınıp değerlendirilmesi, önerilen çözümlerin ise pratik ve çağın ihtiyaçlarına göre olması gerekmektedir. Ayrıca yapılacak çalışmalar süreklilik göstermeli ve gelişmeler de periyodik olarak incelemeye alınmalıdır. 


\section{EXTENDED ABSTRACT}

\section{Examination of PhD Thesis about Teacher Training in Turkey \\ Hanifi Parlar - Meral Halisdemir \\ İstanbul Commerce University}

The teaching profession deserves to be defined as "mothers of professions". Because teaching is a key profession that plays a role in the teaching of cognitive and psychological subtleties of other professions (Işık, Çiltaş \& Baş, 2010). Teacher training is based on a system based on continuous learning, which covers the selection of teacher candidates and faculty education period, internship (transition period to application phase) and in-service training after starting the profession (professional development period). The quantitative (sufficient number) and qualitative characteristics of teachers are directly related to the level of development of a country.

A good and qualified education is carried out by qualified teachers. Therefore, it can be said that "a school is only as good as the teachers in it" (Kavcar, 2002). Increased awareness that "quality education is the key to success" has led to innovations and thus progress. Particularly, remarkable efforts have been made to reveal the teacher profile in recent years (Canado, 2018). In order to train qualified teachers, the education system must be evaluated in all aspects continuously. Studies of universities aiming to train qualified teachers should be reshaped according to the changing time and need and should be up to date and scientific. They also should be equipped with practical techniques and technological infrastructure for the needs of the new generation.

The purpose of this study is to examine "doctoral dissertations on teacher training in Turkey" in terms of content, to set out the current situation, and to lead to possible future studies to be carried out. In line with the stated purpose of the research, answers to the following research questions were sought.

15. How is the distribution of the dissertations by years?

16. How is the distribution of the dissertations by provinces?

17. How is the distribution of the dissertations by universities? 
18. How is the distribution of the dissertations by institutes?

19. How is the distribution of the dissertations by departments?

20. What are the topics of the dissertations?

21. How is the distribution of the dissertations by research methods?

22. How is the distribution of the dissertations by research techniques?

23. What are the data collection tools of the dissertations?

24. What are the samples / working groups of the dissertations?

25 . What are the statistical analyses of the dissertations?

26. What are the written languages of the dissertations?

27. What are the types of resources used in the dissertations?

28. What are the names and titles of dissertation advisors?

In order to access the doctoral dissertations on teacher training in Turkey, doctoral dissertations in the field of educational sciences, which have been archived by CoHE (Turkish Council of Higher Education) Publication Documentation Department since 1986, have been examined as the theoretical universe of the study. 25 dissertations written between 1987 and 2019 were accessed via CoHE National Dissertation Center. The number of theses examined within the scope of the study is 15 since 10 of these are not allowed to be used and published (YÖK, 2018).

In order to collect the data within the scope of this study, a dissertation review form on teacher training and development was prepared. The criteria included in the form, which was given its final form by taking the experts' opinions, are as follows: year, province, university, institute, department, topic, content, research method, research technique, data collection tool, sample / working group, statistical analysis used, written language, resource types used, author gender, consultant gender, consultant name and title.

CoHE National Dissertation Center database has been used to determine the studies to be included in the research. Since 10 of the 25 dissertations accessed were not allowed to be used and published, the number of dissertations examined within the scope of the study was 15.

The data obtained in the research were transferred to the Excel program and analyzes were made using summary tables. The categorical analysis was carried out in line with the principles stated by the authors of the dissertations. The data obtained in the study were analyzed using categorical analysis and frequency analysis techniques, which are among the content analysis types. In the categorical analysis process, the stages of coding data, creating 
and organizing themes, and identifying and interpreting the findings were followed.

As stated in the sub-objectives determined in the study; findings based on the distribution of the dissertations by years, provinces, universities, institutes, departments, subjects, research methods, research techniques, data collection tools, samples / study groups, statistical analysis used, written languages, sources used and the names \& titles of dissertation advisors are presented as graphs and tables.

In this study, dissertations on teacher training in Turkey are examined in terms of their distribution by years, provinces, universities, institutes, departments, topics, contents, research methods, research techniques, data collection tools, samples / working groups, statistical analyses used, written languages, resource types used, author gender, and advisors' genders, names \& titles.

The written languages of the dissertations are generally Turkish, which reduces the readability rate in international literature. Writing and publication of dissertations in English are important for academic satisfaction. It has been observed that incentives are required for graduate researches and dissertations in a foreign language.

The interest in conducting qualitative research has been on the rise in recent years due to the increasing number of research projects in the field of international development. This development can be seen in various studies carried out by organizations and academics in order to understand complex situations better, inform and evaluate future practices and policies (Schulz, 2014). In this study, it was seen that the quantitative method was preferred extensively among the research methods, and the qualitative and mixed models were balanced but less applied. Researchers should be encouraged to study with qualitative and mixed methods as they offer the opportunity to collect more in-depth information. Qualitative research is required, especially to adopt a better educational vision, to focus on basic concepts, to develop practical connections and to synthesize studies that indicate certain improvements collectively (Gaff, 1982). According to the researches, it is known that qualitative data interpretation techniques are developed in the international literature and the results are considered as valid as the results obtained with quantitative data. Now, more data and results can be achieved through a 
qualitative and mixed model. Thus, intricate themes on teacher training will be analyzed in-depth and in all aspects.

Despite the increase in the literature in recent years, very few doctoral dissertations have been written since 1987, which shows the researchers in Turkey hardly give importance to this issue. In order to improve this situation, the researchers who will write a doctoral dissertation should be directed more to this field, be careful about the themes to choose for their doctoral dissertations. They need to handle and evaluate every aspect of the problems observed, and their solutions should be practical and in line with the needs of the age. In addition, the studies to be carried out should be continuous and the developments should be examined periodically.

\section{Kaynakça / References}

Alabaş, R. ve Yılmaz, İ. (2018). Evaluation of candidate teacher training process from the viewpoint of mentor teachers. Journal of Education and Training Studies, 6(11), 12-26.

Androshchuk, I., ve Androshchuk, I. (2017). Peculiarities of future technology teachers' training in Poland and Great Britain. Comparative Professional Pedagogy, 7(1), 51-55.

Atanur Baskan, G. ve Aydın, A. (2006). Türkiye'deki öğretmen yetiştirme sistemine karşılaştırmalı bir bakış. Ç.Ü. Sosyal Bilimler Enstitüsü Dergisi, 15(1), 35-42.

Balbay, S., Pamuk, İ., Temir, T., ve Doğan, C. (2018). Issues in pre-service and inservice teacher training programs for university English instructors in Turkey. Journal of Language and Linguistic Studies, 14(2), 48-60.

Balcı, A. (2003). Eğitim örguitlerine yeni bakış açları: kuram-araştırma ilişkisi II., Kuram ve Uygulamada Eğitim Yönetimi, 33, 26-61.

Canado, M., ve L. P. (2018). Innovations and challenges in CLIL teacher training. Theory Into Practice, 57, 212-221.

Çağatay, Ş. M. (2016). Öğretmen yetiştirmede öğrencilerin akademik, mesleki ve kişisel gelişimlerine iliş̧in yönetsel uygulamalar. Yayınlanmış doktora tezi, Çanakkale On Sekiz Mart Üniversitesi, Çanakkale.

Duman, T. (1988). Türkiye'de öğretmen yetiştirme problemi. Yayınlanmış doktora tezi, Ankara Üniversitesi, Ankara.

Dunkin, M. J. (1996). Types of errors in synthesizing research in education, Review of Educational Research, 66(2), 87-97.

Durdukoca, Ş. F. (2018). Teacher's views on 'teacher training system in Turkey', European Journal of Education Studies, 4(1), 279-308. 
Erginel, S. Ş. (2006). Developing reflective teachers: A study on perceptıon and improvement of reflection in pre-service teacher educatıon. Yayınlanmıs doktora tezi, Yakın Doğu Üniversitesi, Kıbrıs.

Erişen, Y. (2001). Öğretmen yetiştirme programlarına ilişkin kalite standartlarının belirlenmesi ve fakültelerin standartlara uygunluğunun değerlendirilmesi. Yayınlanmış doktora tezi, Ankara Üniversitesi, Ankara.

Ev, H. (1999). Türkiye'de yüksek din öğretimi kurumları programlarının öğretmen yetiştirme bakımından değerlendirilmesi. Yayınlanmış doktora tezi, Dokuz Eylül Üniversitesi, İzmir.

Gaff, J. (1982). Qualitative research methods and educational practice. (E. Kuhnr. S.V.Mariorana Ed.) New Dirrctions /nr Inrtilurional Research: Qunlrtoirvc Mrfhodifor Insfitufronal Research, 34, San Francisco: Josrey-5.

Gelişli, Y. (2000). Öğretmen yetiştirmede Ankara Yüksek Öğretmen Okulu uygulaması. Yayınlanmış doktora tezi, Ankara Üniversitesi, Ankara.

Gülden, Ö. (2013). Teacher cognition in foreign language teacher education: The sources of pre-service teachers' instructional decisions in the classroom. Yayınlanmiş doktora tezi, Istanbul Universitesi, İstanbul.

Harris, D. N., ve Sass T. R. (2011). Teacher training, teacher quality and student achievement. Journal of Public Economics 95, 798-812

Işık, A., Çiltaş, A. ve Baş, F. (2010). Öğretmen yetiştirme ve öğretmenlik mesleği. Atatürk Üniversitesi Sosyal Bilimler Enstitüsü Dergisi,14 (1), 53-62.

Karadağ, E. (2009).Eğitim bilimleri alanında yapılmıs, doktora tezlerinin tematik açdan incelemesi,Ahi Evran Üniversitesi Eğ̈tim Fakuiltesi Dergisi,10(3),75-87.

Karasolak, K. (2017).Öğretmen adaylarının Cumhuriyet'in kuruluşundan gü̈ümüze ögretmenlık mesleğinin tarhsel gelişimi konusundaki bilgi düzeyleri ve bir ders programı önerisi (Türkiye'de öğretmen yetiștirme). Yayınlanmış doktora tezi, Mersin Üniversitesi, Mersin.

Kavcar, C. (2002). Cumhuriyet döneminde dal öğretmeni yetiştirme. Ankara Üniversitesi Eğitim Bilimleri Fakültesi Dergisi, 35(1-2), 1-14.

Kaya, M. (2016). Öğretmen yetiştirme Standartları konusunda bir sistematık literatü̈ inceleme. Yayınlanmış doktora tezi, Eskiş,ehir Osmangazi Universitesi, Eskişehir.

Kazu, H. (1996). Öğretmen yetiştirmede mikro öğretim yönteminin etkililiği. Yayınlanmiş doktora tezi, Firat Üniversitesi, Elazı̆̆.

Onwuegbuzie, A. J., ve Daniel, L. G. (2003). Typology of analytical and interpretational errors in quantitative and qualitative educational research. Current Issues in Education, 6(2), 1-33. 
Özdemir, M. (2010). Nitel veri analizi: Sosyal bilimlerde yöntembilim sorunsalı üzerine bir çalışma, Eskişehir Osmangazi Universitesi Sosyal Bilimler Dergisi,11(1), xxx-xxx.

Saban, A. (2006). Okul teknoloji planlamasi: Ilkö̈retim okulları için uygulamalı bir model önerisi ve ögretmen yetiştirme sistemi açısından sonuçları. Yayınlanmış doktora tezi, Selçuk Üniversitesi, Konya.

Schulz, J. (2014). Research methods in educational leadership and management. International Journal of Research \& Method in Education, 36(2), 204-205.

Şahin, M. (1996). Türkiye'de öğretmen yetiştirme uygulamalarmda yabancı uzmanlarm yeri (1923-1960).Yayınlanmış doktora tezi, Dokuz Eylül Üniversitesi, İzmir.

Şeren, M. (1995). Öğretmen yetiştirmede 3580 sayıl yasayla getirilen parasız yatıllık ve bursluluk uygulaması. Yayınlanmış doktora tezi, Hacettepe Üniversitesi, Ankara.

Turan, E. Z. (2013). Din kuiltürüve ahlak bilgisi ögretmen yetiștirme programlarma ilişkin kalite standartlarmın belirlenmesi: Yayınlanmış doktora tezi, Necmettin Erbakan Universitesi, Konya.

Ültanır, E., ve Ültanır, Y. G. (2018). Comparing teacher competencies formed by professional teaching knowledge lectures in terms of teacher training moves in Turkey and Germany. International Journal of Curriculum and Instruction 10(2), 14-29.

Üstüner, M. (2004). Geçmişten günümüze türk eğitim sisteminde öğretmen yetiştirme ve günümüz sorunları. 20.07.2019 tarihinde https://www.pegem.net/akademi/3-8232-Gecmisten-Gunumuze-Turk-Egitim-Sisteminde-Ogretmen-Yetistirme-ve-Gunumuz-Sorunlari.aspx adresinden erişilmiştir.

Yllman, M. (1987). Türkiye'de ortaöğretime öğretmen yetiştirme sisteminin pedagojik temelleri. Yayınlanmış doktora tezi, Dokuz Eylül Üniversitesi, İzmir.

Yüksek Öğretim Kurulu Ulusal Tez Merkezi (t.y) Tez merkezi. 02.12.2018 tarihinde http://tez2.yok.gov.tr adresinden erişilmiştir.

\section{Kaynakça Bilgisi / Citation Information}

Parlar, H. ve Halisdemir, M. (2020). Türkiye'de öğretmen yetiştirme alaninda yapılan doktora tezlerinin incelenmesi. OPUSUluslararası Toplum Araştırmaları Dergisi, 15(24), 2674-2696. DOI: 10.26466/opus.569629 